\title{
Traditional Arid Lands Agriculture: Understanding the Past for the Future. Edited by Scott E. Ingram and Robert C. Hunt. 2015. The University of Arizona Press, Tucson. 392 pp.
}

\author{
Andrew Gillreath-Brown ${ }^{1 *}$ \\ ${ }^{1}$ Washington State University, Pullman, WA, USA. \\ *andrew.d.brown@wsu.edu \\ Received October 21, 2016 \\ Accepted November 11, 2016
}

OPENठACCESS

DOI 10.14237/ebl.7.1.2016.810

Copyright (c) 2016 by the author(s); licensee Society of Ethnobiology. This is an open-access article distributed under the terms of the Creative Commons Attribution-NonCommercial 4.0 International Public License (https://creativecommons.org/licenses/by-nc/4.0), which permits non-commercial use, distribution, and reproduction in any medium, provided the original author and source are credited.

Archaeological research on arid lands agriculture has typically focused on the how, when, and where of agriculture. Traditional Arid Lands Agriculture offers a fresh perspective by synthesizing past research and also presenting new methods and directions for future arid lands agricultural research. The authors in this edited volume explore what is still unknown about agricultural systems processes. In recent years, archaeologists have begun to connect their research to larger global climate change discussions. The book aims to understand past and contemporary agricultural systems in the United States Southwest and northwestern Mexico (or SW/NW) and what those systems mean for the future of agriculture, water management, and policy, among other things.

The chapters flow together seamlessly—a rarity for edited volumes. In twelve chapters, the authors respond to four main questions posed by editors Scott Ingram and Robert Hunt: "What do we not know about a specific topic related to traditional agriculture? Why do we need to know more? How can we know more? What research questions can we pursue to know more?" (p. 3). These questions implicitly recognize the vast amount of archaeological and ethnological literature on agriculture in the SW/ NW (e.g., Dominguez and Kolm 2005; Ford 1992; Huckell et al. 2002; Mabry 2002, 2005; Muenchrath 1995; Muenchrath et al. 2002; Nabhan 1979; Phillips 2009; Vierra and Ford 2007; Werth 2007; Wills 1995). However, as the authors reveal, archaeology and ethnography have still more to contribute to modern and future societies, as well as to their disciplines.
For example, Karen Adams examines the origins and development of maize (Zea mays) and possibilities for future adaptation or adoption of particular maize varieties that might be more productive in drier conditions. Systematic studies on the productivity of indigenous maize landraces under varying conditions can help productivity estimates under those conditions. If a crop is likely to fail in a given year, then steps such as irrigation or planting a more droughttolerant variety could prevent crop failure.

Jonathan Sandor and Jeffrey Homburg (Chapter 2) suggest that in some instances it is possible to differentiate between soils cultivated in prehistory, and those that have never been cultivated (p. 72-75). For example, the Mimbres agricultural soils had lower carbon and more compaction, whereas non-cultivated soils had higher carbon and less compaction. Soils are part of a dynamic system inextricably linked to water and nutrients. In many cases, prehistoric people were able to maintain the soil (e.g., replenish nutrients) through various methods (e.g., flooding and runoff). A more nuanced understanding of past soils in agricultural settings is an exciting research area because it has the potential to illuminate different agricultural strategies, and their attendant knowledge systems, in a wealth of spatiotemporal contexts. Nonindustrial farmers could still profitably apply ancient/ indigenous practices such as flooding and run-off farming.

Gary Huckleberry's chapter focuses on landscape changes and how those link to climate change. Paleotemperature reconstruction has been difficult in the $\mathrm{SW} / \mathrm{NW}$, so much so that the Intergovernmental 
Panel on Climate Change excluded the SW/NW from their figure on post-glacial temperature changes ( $p$. 90; Jansen et al. 2007:Figure 6.9). One of the reasons that paleo-temperatures are so difficult to track in the $\mathrm{SW} / \mathrm{NW}$ is that the floodplain dynamics for small and large rivers may be influenced by different weather patterns. For example, larger rivers such as the Rio Grande may be influenced by El-Niño-Southern Oscillation-contributing to snowmelt. However, smaller rivers such as the Santa Cruz are more affected by local monsoon patterns (i.e., North American Monsoon). Huckleberry presents a great many references for paleoenvironmental reconstruction of low- and high-frequency temperature records. It can be difficult to determine drought impacts on agricultural systems in floodplain areas, although areas at the upper parts of streams may have been more resilient to drought whereas downstream may have been much more strained. This chapter shows the potential for new research on post-glacial climate changes in the SW/NW that could provide much needed baseline temperature data. Larger weather systems impact local scale weather patterns; however, the extent and relationship between the two scales are not well understood.

Culture, technology, population, and environment collectively have a complex set of relationships that can affect how people choose agricultural strategies, settlement patterns, and whether they adopt and adapt new strategies for coping with change. Scott Ingram develops a technique he calls "archaeological vulnerability assessment" (p. 145), to try to identify the conditions (e.g., population levels, conflict, and environment) that prompt human behavioral responses to dry periods. For example, different groups may or may not depopulate across a region. The rate and intensity at which climate conditions affect population movements or shifts may allow for a more thorough understanding of the processes surrounding human behavior and long term climatic trends. Along similar lines, Robert Hard et al. focuses on the relationship between agricultural strategies (mostly rain-fed farming) and degree of aggregation in Chihuahua, Mexico. Numerous social, demographic, and environmental variables can affect aggregation. It may be beneficial to have a larger labor pool for farming; however, if productive farmland is more dispersed, then it may be more beneficial to not aggregate. Suzanne Fish and Paul Fish explain the complex processes surrounding the development of new or the adaptation of old agricultural subsistence strategies when people aggregate.

Richard Ford and Roxanne Swentzell underscore the importance of learning from the past and present by discussing the beliefs behind agricultural practices and the different water-management strategies for agriculture within the northern Southwest, especially northern New Mexico. Their research explores how communities organize themselves and how that organization can serve water management strategies. Such social considerations are important for understanding the distribution of farming knowledge within kin-based communities. The organization and dissemination of farming knowledge may be helpful for contemporary small farming communities. In a related fashion, archaeological information has helped modern Pueblo people to reconnect with ancient farming techniques, contributing to the rise of permaculture.

Maize has been the dominant focus of attempts to retrodict crop productivity (e.g., Benson et al. 2013; Kohler 2012) due to the wide acceptance that maize was the dominant component in the SW/NW prehistoric diet; beans, squash, cotton, and ruderals have not been given similar research attention. Alan Sullivan argues that we should think beyond the "corn paradigm" (p. 273), especially since the evidence for maize agriculture in the Grand Canyon area is more ambiguous than in most other portions of the Southwest. Through fire, past indigenous groups in the Grand Canyon area may have actively promoted ruderals instead of maize. Robert Hunt explores how irrigated Mesoamerican crops (i.e., maize, beans, squash, and cotton) are affected by changes in water availability in the Sonoran Desert. This has important implications for understanding prehistoric farming systems and how people adapted. Some plants that we have long viewed as weeds or as unimportant may prove to be extremely useful to people in stressful times. Although not mentioned by Sullivan, it would be interesting to extend Hunt's methods to the growing requirements and water thresholds of ruderals under varying environmental conditions to understand ruderal productivity.

Kyle Woodson focuses on ways to refine our approach on estimating past streamflow from present streamflow (i.e., retrodiction) and flooding, since the timing and magnitude of floods are difficult to determine from retrodictions. Flooding could have had negative impacts on Hohokam irrigation canal infrastructure. By refining streamflow retrodiction 
methods and explicitly stating retrodicted data limitations, researchers could then critically use the data to address questions about how humans coped with flooding and how flooding may have affected infrastructure. While flooding can have negative impacts, floods of short duration and small magnitude may play a positive role in replenishing soil nutrients and moisture. Appropriate irrigation infrastructure allows people to take advantage of episodic flooding and precipitation to turn a seemingly non- or lowproductive environment into a productive one, as in the extremely dry environment of the Atacama Desert in Chile (Parcero-Oubiña et al. 2016).

Michael Adler explores the role of archaeologists in 'litigation-based research' for groups wanting to establish water rights. Canal irrigation in the northern Rio Grande is not as well-understood as in the Hohokam case in southern to central Arizona. Archaeologists have been relying upon modeling to explore various questions such as food production. Ground truthing is needed to increase "our empirical knowledge of spatial and temporal diversity in water management techniques" (p. 222). Dating canals through use of ${ }^{14} \mathrm{C}$, AMS, and OSL is the main way to determine when the canals were created. Archaeologists should be cautious and thorough in their review of irrigation structure data when contributing to water rights cases.

"Utilitarian archaeology," which focuses on how archaeological data and research can contribute to solving modern problems, is becoming more important as funding and scientific agencies desire to see the merit of archaeological research beyond the discipline itself. In Paul Minnis' conclusion to the book, he gets to the heart of the matter when he says, "Instead of the present being used to help us understand the past, the past is used to help solve specific problems in the present" (p. 364).

Although the authors engage with climate in very creative ways, I was dissatisfied with the lack of discussion on the different types of drought and the varying levels of impact on agricultural systems. Huckleberry does, however, discuss larger scale climatic patterns. For example, Ingram (p. 133-134) does distinguish the difference between the use of drought and dry-periods-the former being defined as an extended period of water shortage which has detrimental effects on the physical environment and/ or people, and the latter defined by specific precipitation or temperature thresholds. While the term dry- period is a less loaded term than drought, it is important to understand the different types of drought, which are meteorological, agricultural, hydrological, and socioeconomic (Quiring 2009). Different kinds of droughts may have affected people, crops, and vegetation in different ways.

The authors cover a wide range of agricultural topics, however, these are limited in scope to either specific geographic regions or the range of a topic (e.g., dryland farming focus in Chapter 2). The volume editors and contributors are explicit about these limitations throughout the book, though the hope is that the methods explained here can be applied to other arid regions. Herein lies the great potential for many new research projects surrounding traditional arid land agriculture.

The book will be useful for researchers looking for new projects or refining old projects, for newcomers to arid lands agriculture, for archaeological background research on arid agriculture, for modern and prehistoric subsistence strategies, and for government and policy-makers aiming to create a sustainable future. Researchers have been taking on the challenges of using new methods to understand past agricultural systems and the relationship between people and agriculture (e.g., Bocinsky et al. 2016; Brown 2016; d'Alpoim Guedes et al. 2015). The authors creatively highlight a bright future for archaeological research, as well as for ethnography and ethnobiology (e.g., Nabhan 2016).

The studies in this book not only help us to gain a better understanding of past agricultural practices in many different arid contexts, but the larger impacts of being able to study long-term change using various disciplines (e.g., hydrology, geomorphology, soils, climatology) will allow for these studies to be applied to modern needs.

\section{References Cited}

Benson, L. V., D. K. Ramsey, D. W. Stahle, and K. L.

Petersen. 2013. Some Thoughts on the Factors

that Controlled Prehistoric Maize Production in

the American Southwest with Application to

Southwestern Colorado. Journal of Archaeological

Science 40:2869-2880. DOI:10.1016/

j.jas.2013.03.013.

Bocinsky, R. K., J. Rush, K. W. Kintigh, and T. A. Kohler. 2016. Exploration and Exploitation in the Macrohistory of the Pre-Hispanic Pueblo Southwest. Science Advances 2:e1501532. DOI:10.1126/ sciadv.1501532. 
Brown, A. D. 2016. Looking Outward from the Village: The Contingencies of Soil Moisture on the Prehistoric Farmed Landscape Near Goodman Point Pueblo. Master's Thesis, Department of Geography, University of North Texas, Denton, TX. Available from UNT Digital Library: http:// digital.library.unt.edu/ark:/67531/

metadc862755/. DOI:10.13140/

RG.2.2.17680.00004.

d'Alpoim Guedes, J., S. W. Manning, and R. K. Bocinsky. 2015. A 5,500-Year Model of Changing Crop Niches on the Tibetan Plateau. Current Anthropology 57:517-522. DOI:10.1086/687255.

Dominguez, S., and K. E. Kolm. 2005. Beyond Water Harvesting: A Soil Hydrology Perspective on Traditional Southwestern Agricultural Technology. American Antiquity 70:732-765.

DOI:10.2307/40035872.

Ford, R. I. 1992. An Ecological Analysis Involving the Population of San Juan Pueblo, New Mexico, with a new introduction. Garland Press, New York, NY.

Huckell, B. B., L. W. Huckell, and K. K. Benedict. 2002. Maize Agriculture and the Rise of Mixed Farming-Foraging Economies in Southeastern Arizona during the Second Millennium BC. In Traditions, Transitions and Technologies: Themes in Southwestern Archaeology, edited by Sarah H. Schlanger, pp. 137-159. University of Colorado Press, Boulder, CO.

Jansen, E., J. Overpeck, K. R. Briffa, J. C. Duplessy, F. Joos, V. Masson-Delmotte, D. Olago, B. OttoBliesner, W. R. Peltier, S. Rahmstorf, and R. Ramesh. 2007. Paleoclimate. In Climate Change 2007: The Physical Science Basis. Working Contribution of Working Group I to the Fourth Assessment Report of the Intergovernmental Panel on Climate Change, edited by S. Solomon, D. Qin, M. Manning, Z. Chen, M. Marquis, K. B. Averyt, M. Tignor, and H. L. Miller. Cambridge University Press, Cambridge, United Kingdom and New York, NY, USA. Available at: https://www.ipcc.ch/ publications_and_data/ar4/wg1/en/ch6.html. Accessed on October 14, 2016.

Kohler, T. A. 2012. Modeling Agricultural Productivity and Farming Effort. In Emergence and Collapse of Early Villages: Models of Central Mesa Verde Archaeolo$g y$, edited by T. A. Kohler and M. D. Varien, pp. 85-112. University of California Press, Berkeley, CA.

Gillreath-Brown. 2016. Ethnobiology Letters 7(1):99-103
Mabry, J. B. 2002. The Role of Irrigation in the Transition to Agriculture and Sedentism in the Southwest: A Risk Management Model. In Traditions, Transitions, and Technologies: Themes in Southwestern Archaeology, edited by S. H. Schlanger, pp. 178-199. University of Colorado Press, Boulder, CO.

Mabry, J. B. 2005. Diversity in Early Southwestern Farming and Optimization Models of Transitions to Agriculture. In Subsistence and Resource Use Strategies of Early Agricultural Communities in Southern Arizona, edited by M. W. Diehl, pp. 113-152. Anthropological Papers, No. 34. Center for Desert Archaeology, Tucson, AZ.

Muenchrath, D. A. 1995. Productivity, Morphology, Phenology, and Physiology of a Desert-adapted Native American Maize (Zea mays L.) Cultivar. Ph.D. dissertation, Department of Agronomy, Iowa State University, Ames, IA. Available at: http://lib.dr.iastate.edu/rtd/10967/. Accessed on September 19, 2016.

Muenchrath, D. A., M. Kuratomi, J. A. Sandor, and J. A. Homburg. 2002. Observational Study of Maize Production Systems of Zuni Farmers in Semiarid New Mexico. Journal of Ethnobiology 22:1-33.

Nabhan, G. P. 1979. The Ecology of Floodwater Farming in Arid Southwestern North America. Agro-ecosystems 5:245-255. DOI:10.1016/0304-3746 (79)90004-0.

Nabhan, G. P., ed. 2016. Ethnobiology for the Future: Linking Cultural and Ecological Diversity. University of Arizona Press, Tucson, AZ.

Parcero-Oubiña, C., P. Fábrega-Álvarez, D. Salazar, A. Troncoso, F. Hayashida, M. Pino, C. Borie, and E. Echenique. 2016. Ground to Air and Back Again: Archaeological Prospection to Characterize Prehispanic Agricultural Practices in the Highaltitude Atacama (Chile). Quaternary International. DOI:10.1016/j.quaint.2015.12.050.

Phillips Jr, D. A. 2009. Adoption and Intensification of Agriculture in the North American Southwest: Notes Toward a Quantitative Approach. American Antiquity 74:691-707.

Quiring, S. M. 2009. Developing Objective Operational Definitions for Monitoring Drought. Journal of Applied Meteorology and Climatology 48:1217-1229. DOI:10.1175/2009JAMC2088.1. 
Vierra, B. J., and R. I. Ford. 2015. Foragers and Farmers in the Northern Rio Grande Valley, New Mexico. Kiva 73:117-130. DOI:10.1179/ kiv.2007.73.2.002.

Werth, L. C. 2007. Characterization and Classification of Native American Maize Landraces from the Southwestern United States. Retrospective Theses and Dissertations. Paper 14628. Department of Agronomy, Iowa State University, Ames, IA. Available at: http://lib.dr.iastate.edu/cgi/ viewcontent.cgi?article $=15627 \&$ context $=$ rtd. Accessed on September 19, 2016.

Wills, W. H. 1995. Archaic Foraging and the Beginning of Food Production in the American Southwest. In Last Hunters-First Farmers: New Perspectives on the Prehistoric Transition to Agriculture, edited by $\mathrm{T}$. Price and A. Gebauer, pp. 215-242. School of American Research Press, Santa Fe, NM. 